\section{ECCOMAS} Proceedia
COMPDYN 2021 Computational Methods in Structuratic Conference on namics and Earthquake Engineering

M. Papadrakakis, M. Fragiadakis (eds.) Streamed from Athens, Greece, 28 - 30 June 2021

\title{
MOMENT-CURVATURE DIAGRAMS FOR CLT PANELS ACCOUNTING FOR ORTHOGONAL TO GRAIN COMPRESSION TIMBER PROPERTIES
}

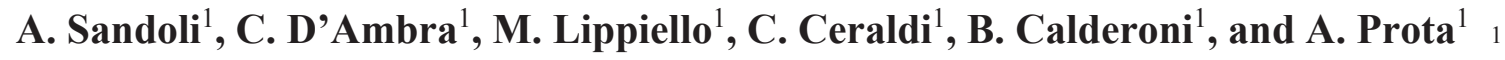 \\ Dept. of Structures for Engineering and Architecture \\ via Claudio 21,80125, Naples, Italy \\ e-mail: antonio.sandoli@unina.it., claudio.dambra@unina.it,maria.lippiello@unina.it, \\ ceraldi@unina.it, calderon@unina.it, aprota@unina.it
}

\begin{abstract}
Typically, panel-to-panel and panel-to-foundation connection zones in Cross-Laminated Timber (CLT) walls consist of steel-to-timber mechanical connections (hold-downs and anglebrackets) and timber-to-timber contact. While hold-downs and angle brackets are extensively studied in literature, the role of timber-to timber contact is underestimated. The platform constructional technology used for build CLT walls requires that the vertical timber panels compresses the horizontal CLT floors, engaging the orthogonal to grain timber properties in the seismic response.

This paper discusses a new development concerning a theoretical sectional model for CLT panels proposed by the authors in a recent work, where strength of the panels subjected to combined axial force and bending moment was studied accounting for orthogonal to grain timber properties. As advancement, a theoretical moment-curvature model for CLT panels is proposed in this paper and the displacement capacity (i.e., ductility) is investigated. The main parameters which affect the ductile behavior of the panels have been studied by means of parametric analyses, i.e. varying cross-section dimensions, amount of axial force, and holddowns resistance.

Theoretical results have been also compared with numerical ones derived from a bidimensional finite element model developed by the authors and a good matching between the results has been highlighted.
\end{abstract}

Keywords: CLT panels, Orthogonal to grain compression, Connection Modelling, Theoretical model, Moment-Curvature diagrams.

ISSN:2623-3347 C 2021 The Authors. Published by Eccomas Proceedia.

Peer-review under responsibility of the organizing committee of COMPDYN 2021.

doi:10.7712/120121.8634.18809 


\section{INTRODUCTION}

Cross-Laminated Timber (CLT) represents a high efficient engineered mass timber product originated in Austria in the early 1990s. In Europe, CLT panels are one of the most diffused mass timber product used for low and mid-rise residential and non-residential buildings in seismic prone area. It has been estimated that the global annual production of CLT is growing exponentially in Europe, from $25.000 \mathrm{~m}^{3}$ in 1996, up to 1.2 million of $\mathrm{m}^{3}$ in 2020 [1]. Nevertheless, a significant annual increase of the manufactured CLT has been also recorded in the United States, Canada, Australia, Japan and New Zealand [2-4].

Shake-table tests demonstrated the satisfactory seismic behavior of multi-story CLT buildings. They resisted seismic accelerations up to $0.82 \mathrm{~g}$ for a seven story building [5] and up to $1.52 \mathrm{~g}$ for a two-story building [6] thanks to their good dissipative behavior. The dissipation is mainly concentrated in the panel-to-panel and in panel-to-foundation mechanical connection zones, generally composed by thin-walled steel plates nailed or screwed to the vertical panels and bolted in foundation, named as Hold-Downs (HDs) and Angle-Brackets (ABs). HDs are devoted to withstand tensile forces produced by the overturning moments, while ABs resist to shear forces. Compression forces, instead, are faced by timber-to-timber or timber-tofoundation contact.

Experimental local tests on mechanical connections aimed at investigating their cyclic behavior highlighted that ductile failure mechanisms can be achieved when properly designed [7, 8]. Contrariwise, brittle failure mechanisms could occur if the requirements for end and edge distances are not respected [9]. Commonly, in timber practice it is assumed that ductile mechanisms are those respecting the Johansen's failure modes [10] also included in Eurocode 5 [10]. Although provided of an appreciable dissipative behavior, such mechanisms entail significant damaging of vertical timber panels making them unusable after the seismic event [12].

In addition to the seismic resistance, modern seismic design approaches based on the Performance-Based Design require that also damaging of structural (and non-structural) components should be prevented or reduced as far as possible. Thus, alternative connection systems based on the 'plug and play' concept have been introduced by researchers [13-15]. They consist of replaceable steel fuses, or other steel-based material, fastened to timber panels which dissipate energy through the cyclic plasticization of the steel parts only, while timber parts remain elastic. Steel parts, which can be substituted after the seismic event, are devoted to prevent the damaging of timber CLT panels and consequently to reduce economical losses for their repairing.

To date, theoretical models for evaluating flexural load-bearing capacity of CLT panels subjected to combined bending and axial force are presented in literature, taking into account the contribution of the HDs and ABs at the base of the panels [16, 17]. Two are the main shortcomings that characterize such methods: $a$ ) the role of timber-to-timber contact is under evaluated, $b$ ) no formulation for evaluating the ductility are presented.

Usually, the timber-to-timber contact is modelled considering the parallel to grain direction timber properties [19]. Contrariwise, due to the platform constructional technology used to realize CLT buildings, the perpendicular to grain timber properties (i.e., Young's modulus, ultimate compression strength and strain) are unavoidably involved in the seismic behavior of the panel. In fact, at each story the horizontal CLT floor panels are inserted between two consecutive vertical CLT panels, while at ground level a horizontal timber beam is commonly interposed between vertical panel and foundation (Fig. 1). Conversely, if interposed timber beams are not used and the vertical panels are directly placed on the reinforced concrete foundation, the parallel to grain timber properties must be employed in the calculations. 
Nowadays, no specific information relative to the orthogonal to grain compressive behavior of CLT elements are provided in the European standards (with exception for the Austrian National Annex [20]), as well as limited experimental and numerical results can be found in literature [20-22].

This papers deals with a new development of a theoretical sectional model for CLT panels subjected to combined axial force and bending moment, presented by the authors in a recent paper [23]. The method presented in [23] permitted to define the flexural load-bearing capacity of the panels through axial force-bending moment interaction domains. As advancement, a theoretical moment-curvature (M- $\chi$ ) model for CLT panels is herein presented.

A parametric study aimed at investigating the influence of different factors on the postelastic displacement capacity of the panels - such as percentage of reinforcement ratio (intended as the contribution provided by HDs in tension), the amount of axial force and the length-to-width ratios of the panel cross-section - has been carried out. Due to the absence of experimental tests, the validity of the proposed $\mathrm{M}-\chi$ diagrams has been assessed by comparison with a finite element numerical model of the CLT panels developed by the authors.

The results allowed to investigate the role of the mechanical connections and timber-totimber contact on the ductile behavior of the panels, highlighting a good matching between theoretical and numerical results. Moreover, the comparative analyses permitted to develop a design-oriented approach for evaluating the ultimate curvature and the ultimate bending moment of the panels through closed-formulas, useful in engineering practice.

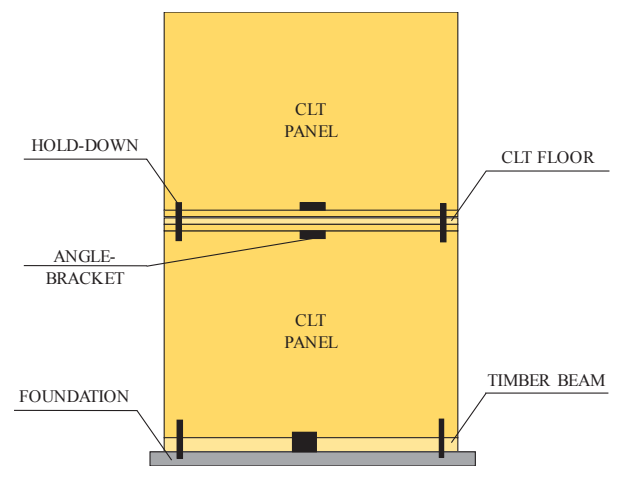

Figure 1: Platform constructional technology for CLT buildings.

\section{CONNECTIONS MECHANICAL MODEL}

With aim of calculating the flexural load-carrying capacity of CLT panels under gravity and horizontal loads, different methods for schematizing the panel to panel and the panel to foundation connection zone are proposed in literature. These methods, extensively compared in [17] and in [12], are mainly based on static equilibrium equations. They assume the hypothesis that CLT panel behaves as a rigid-body with deformations concentrated in the mechanical connections: the overturning moments are faced by HDs (tension) and timber-totimber contact (compression), while shear forces are resisted by ABs exclusively. Due to buckling, the contribution of HDs under compression is generally disregarded.

Recently, a mechanical model to schematize the connections has been proposed by the authors in [23]. The goal of the method was that of determining the flexural load-bearing capacity of CLT panels and deriving the axial force-bending moment interaction domains. The same model has been employed for deriving moment-curvature diagrams in the present paper, allowing to investigate the post-elastic displacement capacity of the CLT panels with mechanical connections at the base. 
The proposed model could be considered as an advancement with respect to the method presented in [16], in which the behavior of panel-to-panel and panel-to-foundation connection zone has been modelled in analogy with Reinforced Concrete (RC) cross-sections: HDs are considered as the tensile-resistant elements which yield in tension, while timber-to-timber contact is assimilated to compressed concrete whose behavior is limited to the elastic field. For timber-to-timber contact, the maximum compression strength is assumed equal to that in parallel to grain direction, while the Young's modulus is that in orthogonal to grain direction. Conversely, for timber-to-RC foundation contact the parallel to grain Young's modulus is considered (while the compression strength remains that in parallel direction).

In the proposed method, instead, both orthogonal or parallel to grain timber properties for panel-to-foundation connections can be used, as a function of constructional technology used at the ground level (i.e., if interposed timber beam between vertical panel and foundation is used or not). While, only the orthogonal to grain contact is assumed for panel-to-panel connections at upper storey.

\subsection{Orthogonal to grain compression behavior}

Orthogonal to grain compression situations are a direct consequence of the platform constructional technology used to build CLT structures. Under seismic actions, the vertical panel rocks around a pivot point - often not coincident with the corner of the panel - loading in orthogonal to grain direction the CLT timber floors at upper storey or the timber beams at ground floor when present [24] (Fig. 2).

This phenomenon cannot be neglect in evaluating the load-carrying capacity of the panel, because:

(i) the orthogonal to grain compressive strength $f_{\mathrm{c}, 90}$ is less than that in parallel to grain di-

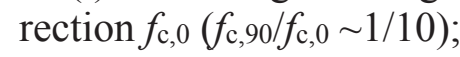

(ii) the Young's modulus in perpendicular direction E90 is much less than that in parallel direction $E_{0}\left(E_{90} / E_{0} \sim 1 / 30\right)$;

(iii) the orthogonal to grain ultimate strain $\varepsilon_{\mathrm{c}, 90}$ is much higher than in parallel direction $\varepsilon_{\mathrm{c}, 0}$ $\left(\varepsilon_{\mathrm{c}, 0 /} / \varepsilon_{\mathrm{c}, 90} \sim 1 / 10-1 / 15\right)$.

Although the orthogonal to grain compressive behavior for mono-dimensional elements has been extensively studied and tests procedures codified $[25,26]$, few are the results available for CLT specimens. Some experimental results on CLT specimens subjected to perpendicular to grain compression loads, with different loads configurations, are presented in [20$22]$. Experimental stress $(\sigma)$-strain $(\varepsilon)$ diagrams are characterized by a first nonlinear elastic branch, followed by a significant perfectly-plastic branch with hardening at the end.

By a theoretical point of view, the shape of the $\sigma-\varepsilon$ diagram can be described by parabolarectangle constitutive law (Fig. 3). The shape is similar to that of concrete subjected to compression and then, by analogy, the same constitutive law suggested for concrete in the Eurocode 2 [27] has been adopted to describe the orthogonal to grain compressive behavior of timber. The parabolic and the constant branch are described by the following equations, respectively:

$$
\begin{array}{ll}
\sigma=\eta(2-\eta) f_{c, 90, d} & 0 \leq \eta \leq 1 \\
\sigma=f_{c, 90, d} & 1 \leq \eta \leq \varepsilon_{c, 90, u} / \varepsilon_{c, 90, e l}
\end{array}
$$

where $\eta=\varepsilon / \varepsilon_{\mathrm{c} ; 90, \text { el }}$ represents the ratio between the values of strain $(\varepsilon)$ included into the interval $\left[0 ; \varepsilon_{\mathrm{c}, 90, \mathrm{el}}\right]$ for eq. (1) and into the interval $\left[\varepsilon_{\mathrm{c}, 90, \mathrm{el} ;} \varepsilon_{\mathrm{c}, 90, \mathrm{u}}\right]$ for eq. (2); while $\varepsilon_{\mathrm{c}, 90, \mathrm{el}}$ and $\varepsilon_{c, 90, u}$ represent the limit elastic and ultimate strain of timber, respectively. 
Contrarily to the maximum perpendicular compression strength, whose values are codified also by Eurocode 5 [11], for orthogonal to grain ultimate strain no values are suggested by codes. Experimental studies conducted by Serrano and Enquist [20] and by Brandner [22] on CLT panels under compression shown significant plastic strains, greater than $15-20 \%$ at the end of tests.

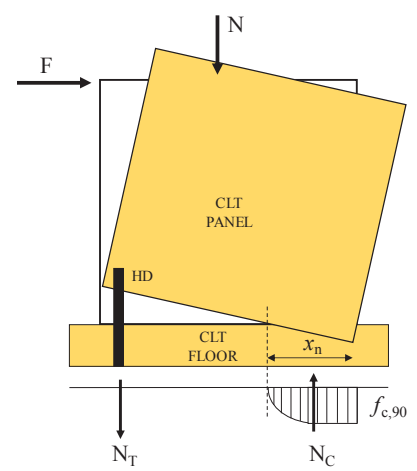

Figure 2: Orthogonal to grain crushing of CLT floors due to rocking of the vertical panel.

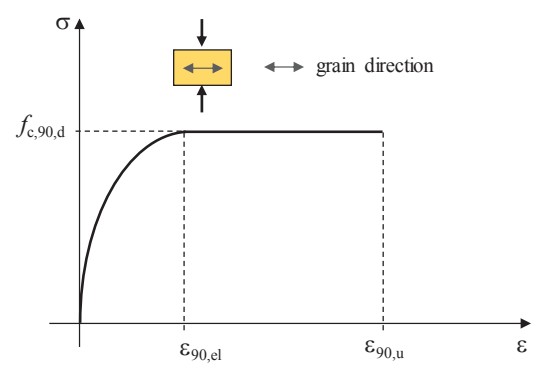

Figure 3: Constitutive stress-strain behavior for timber compressed in orthogonal to grain direction.

\subsection{Cross-sectional behavior modelling}

In this paper, a model for describing the cross-sectional behavior of CLT panels developed by analogy with RC cross-sections is presented. The term 'section' indicates the timber-totimber contact area defined between the vertical and the horizontal timber panels.

In this model, tensile-resistant contributions are provided by hold-downs (HDs) exclusively, or combining hold-downs and angle brackets $(A B S)$ if both are assumed able to resist tensile forces $[7,9,28]$. Instead, compression forces are totally faced by timber-to-timber or by timber-to-RC foundation contact.

By analogy with RC, three different behavioral stages for the cross-section have been defined (Fig. 4): stage $I$, in which both timber-to-timber contact and tensile-resistant elements behave elastically both in compression and in tension; stage $I I$, when the maximum strength into timber-to-timber compressed corner is reached, whereas tensile-resistant elements still work in linear-elastic field (or vice versa); stage III, when the orthogonal to grain ultimate strain at compressed corner is attained, while tensile-resistant elements are 'yielded'.

It should to be highlighted that the proposed theoretical method is of general validity. In fact, failure mechanisms based on $(A)$ timber embedding combined with metal fasteners [10, 11] or on $(B)$ yielding of metal steel elements (steel plates, steel fuses based on 'plug and play' concept, etc.) with timber in elastic field can be both implemented. As already noted in Sect. 1, the failure mechanisms $(B)$ are far preferred to avoid permanent damage into timber panels in case of earthquakes and represents a new frontier for low-damage and more sustainable CLT buildings $[12,13]$. 


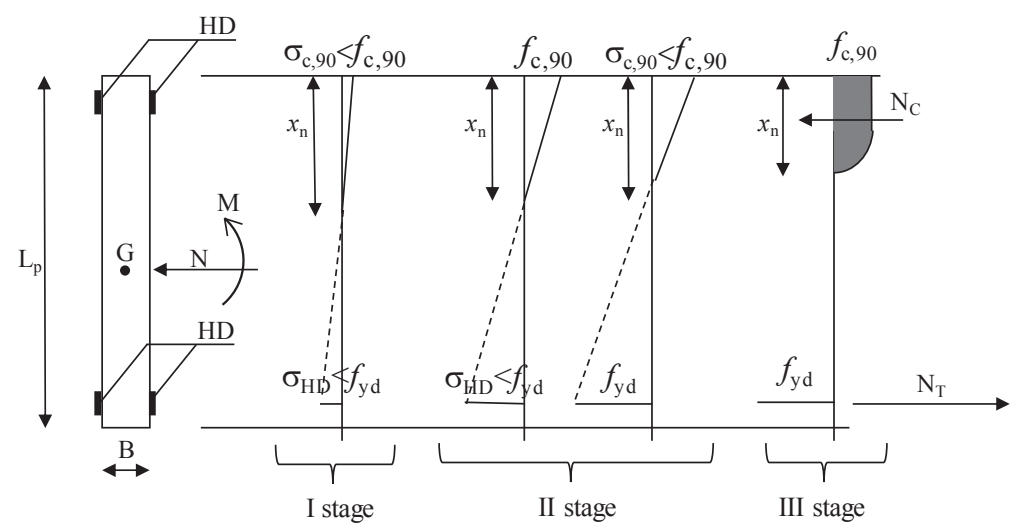

Figure 4: Normal stress diagrams for the three behavioral stages.

\section{THEORETICAL MOMENT-CURVATURE DIAGRAMS}

Moment-curvature diagrams represent a useful tool for evaluating the ductile behavior of CLT panels subjected to combined horizontal seismic actions and gravity loads.

The M- $\chi$ cross-sectional behavior has been investigated based on the Euler-Bernoulli hypothesis concerning the conservation of plain transversal cross-sections after the deformation. Moreover, it has been assumed that the mechanical connections fail according to the mechanism type-B only, thus maximum yielding strength and ultimate strain in tension of thin-steel plates (e.g., HDs) are involved in the plastic mechanism. In other terms, a mechanical connection based on a 'plug and play' system, or having innovative dog-bone shaped hold-downs presented in [23] has been herein considered. While for the compressed timber the orthogonal to grain direction properties have been taken into account.

On the other side, also failure mechanisms type-A (Johansen's mechanisms) can be implemented in the proposed model, but with the disadvantage that it is more complex to establish a suitable and reliable value of ultimate strain (axial elongation) due timber-to-steel interaction. In fact, available experimental tests provided only maximum values of axial displacement in timber-to-steel interaction because it is difficult to evaluate the corresponding strain.

Constitutive stress-strain behaviors adopted for timber (Fig. 5a) and steel (Fig. 5b) in this paper are represented in Fig. 5. For timber the parabola-rectangle constitutive behavior has been obtained by using the eqs. (1) and (2), with $\varepsilon_{\mathrm{c}, 90, \mathrm{u}}=5 \%$ (assumed as a reasonable value by the authors), $\varepsilon_{\mathrm{c}, 90, \mathrm{el}}=0.75 \%$ and design perpendicular to grain compression strength $f_{\mathrm{c}, 90, \mathrm{~d}}=2.90$ $\mathrm{MPa}$. The latter has been evaluated considering the spatial dispersion of locally applied compression perpendicular to grain stresses: the increasing coefficient $k_{\mathrm{c}, 90}$ (in this case equal to 1.50) has been multiplied for the perpendicular compression strength according to [11]. Note that the material properties of the 3-ply CLT panels have been derived from ETA-14/0349 [29], as those corresponding to solid wood of class C24.

For steel, instead, an elastic-perfectly plastic constitutive stress-strain behavior has been adopted, considering steel-type S275 (as defined in Eurocode 3 [30]) with design yielding strength $f_{\mathrm{yd}}=261.9 \mathrm{MPa}$, yielding strain $\varepsilon_{\mathrm{HD}, \mathrm{y}}=0.12 \%$ and ultimate strain $\varepsilon_{\mathrm{HD}, \mathrm{u}}=7 \%$. 


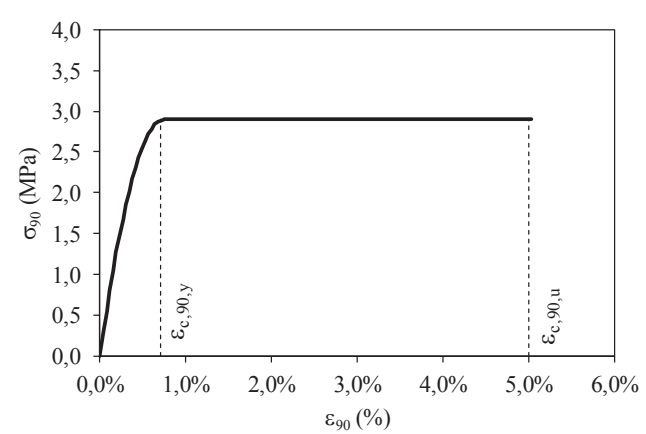

a)

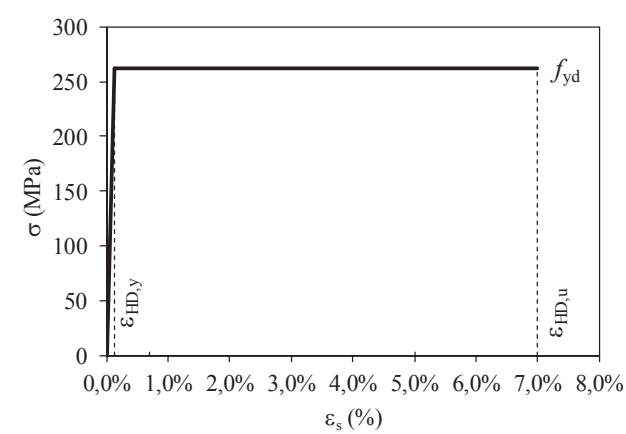

b)

Figure 5: Constitutive stress-strain behavior for (a) timber compressed in orthogonal to grain direction, (b) steel in tension.

\subsection{Methodology}

Moment-curvature diagrams have been obtained by means of an iterative procedure, schematically represented in the flowchart reported in Fig. 6 . The procedure consists of assigning a pair of first attempt values $\left(\chi, x_{\mathrm{n}}\right)$ - where $\chi$ represents the curvature of and $x_{\mathrm{n}}$ the neutral axis depth - for panel to panel or panel to foundation contact cross-section and of verifying, by means of equilibrium conditions, that such assumption is right. In the following is summarized step-by-step the procedure:

(i) assign attempt values of $\left(\chi, x_{\mathrm{n}}\right)$;

(ii) calculation of values of strains $(\varepsilon)$ corresponding to the couple $\left(\chi, x_{\mathrm{n}}\right)$ in each point of the cross-section thanks Euler-Bernoulli hypothesis;

(iii) calculation of normal stresses associated to these strains from the constitutive stressstrain constitutive behavior adopted for both CLT and HD;

(iv) determination of both internal compression and the tension resultant forces by integrating the stresses diagram over the cross-sections;

(v) the supposed values of $\chi$ and $x_{\mathrm{n}}$ are right if the translation equilibrium over the crosssection among the internal forces and the applied axial force is satisfied. If it is not satisfied, the procedure must be reiterated by choosing another couple of values $\left(\chi, x_{\mathrm{n}}\right)$; if it is satisfied, the corresponding moment $(M)$ can be determined through the equilibrium rotation (with respect to the center-of-gravity of the section).

To obtain the entire $M-\chi$ diagram, the procedure must be developed for the interval between $\chi=0$ and the ultimate curvature $\chi \mathrm{u}$.

\subsection{Parametric analyses results}

Based on the iterative procedure, theoretical $\mathrm{M}-\chi$ diagrams have been obtained. In particular, parametric analyses considering different factors which influence the cross-sectional behavior have been conducted. The investigated parameters are listed in the following:

1. geometrical 'reinforcement' percentage ratio:

$$
\rho=\frac{A_{H D}}{A_{C L T}}(\%)
$$

where AHD represent the cross-section area of HDs involved in the plastic mechanism, while ACLT is the cross-section area of the CLT panel.

2. Cross- section slenderness ratio: 


$$
\lambda=\frac{L_{p}}{B}
$$

where $\mathrm{L}_{\mathrm{p}}$ represents the panel length, while B the panel width.

3. Dimensionless axial force ratio:

$$
v=\frac{N_{E d}}{N_{R d}}(\%)
$$

where $\mathrm{N}_{E d}$ is the acting axial force and $\mathrm{N}_{\mathrm{Rd}}$ the ultimate strength of the fully compressed section.

In Figure 7 are represented the $M-\chi$ diagrams obtained by varying the geometrical 'reinforcement' percentage ratios, from $\rho=0 \%$ to $\rho=0.30 \%$. To obtain these diagrams, a CLT panel having a slenderness ratio $\lambda=18$ (cross-section with $\mathrm{L}_{\mathrm{p}}=2500 \mathrm{~mm}$ and $\mathrm{B}=135 \mathrm{~mm}$ ) and an axial force ratio $v=20 \%$ has been considered as representative and however realistic for CLT buildings. As it can be noted in Figure 7, for increasing value of $\rho$ the ultimate moments of the panel increases, whereas the ductility reduces more than $50 \%$ passing from $\rho=0 \%$ to $\rho=0.30 \%$. This means that higher reinforcement percentages (i.e., several HDs) lead the panel toward brittle behavior, in the face of increase of flexural resistance.

On the same diagrams, squared blue dots indicate the curvature corresponding to the HDs which yield in tension $(\varepsilon H \mathrm{HD}, \mathrm{y})$, green dots the points in which the timber-to-timber contact attains its yielding strain $\left(\varepsilon_{c, 90, y}\right)$, while red triangles the achievement of the ultimate strain of

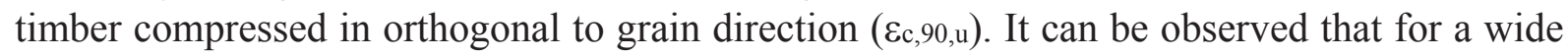
range of $\rho$ (from 0 to $0.24 \%$ ) the yielding of HDs in tension precede that of timber in compression, while for $\rho$ greater than $0.24 \%$ timber yield before than HD. Moreover, as $\rho$ increases the interval of the first yielding curvature between HDs and compressed timber reduces.

In Figure 8 are represented the $M-\chi$ diagrams for slenderness ratios ranging from $\lambda=10$ to $\lambda=38$, relative to a panel having constant width (B) equal to $135 \mathrm{~mm}$ while the panel length $\left(\mathrm{L}_{\mathrm{p}}\right)$ varies from 150 to $500 \mathrm{~mm}$. The $\mathrm{M}-\chi$ diagrams show that as $\lambda$ increases the ductility decreases, while ultimate moment increases. Also in these diagrams the yielding in tension of the HDs anticipates that of timber stressed in orthogonal to grain compression, whilst the ultimate curvature is attained when the compressed timber reaches the its ultimate strain at the compressed edge.

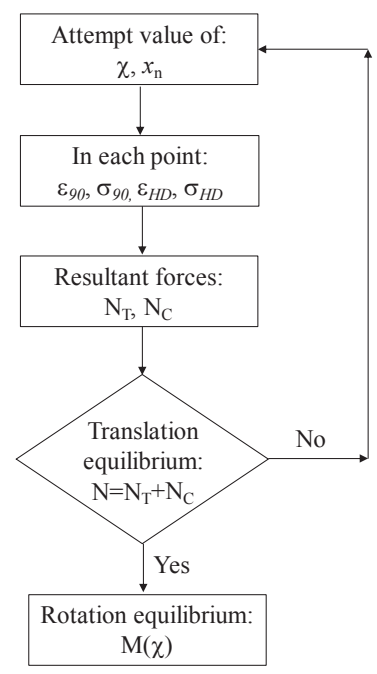

Figure 6: Flowchart of the iterative procedure developed for obtaining the $M-\chi$ diagrams. 
In Figure 9 instead are reported the $M-\chi$ diagrams for dimensionless axial forces ratios varying from $0 \%$ (pure bending) to $40 \%$. Again, the yielding of HDs precedes that of compressed timber, except for the case having $v=40 \%$. This latter finding is convincing, because high values of the applied axial force involves significant orthogonal to grain compression stresses on the cross-section which lead to a 'yielding' of timber before of HDs. For the sake of simplicity, the curve with $v=50 \%$ has not been reported in the Figure because resulted quite superimposed with the curve having $v=40 \%$ : This is reasonable observing the N-M interaction domains: about $v=40-50 \%$ the domain varies smooth, such that ultimate moment (which is reached at $v=50 \%$ ) varies little from $v=40 \%$ to $v=50 \%$ [23]. On the contrary, passing from $\mathrm{v}=40 \%$ to $50 \%$ the ductility reduces further.

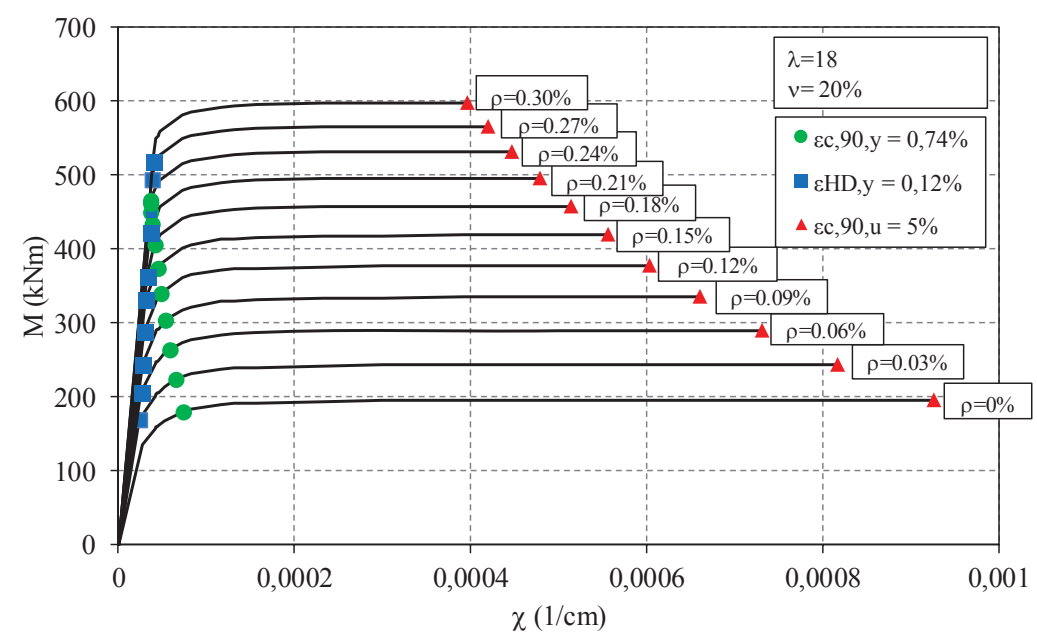

Figure 7: Moment-curvature diagrams obtained varying the 'reinforcement' area ratio.

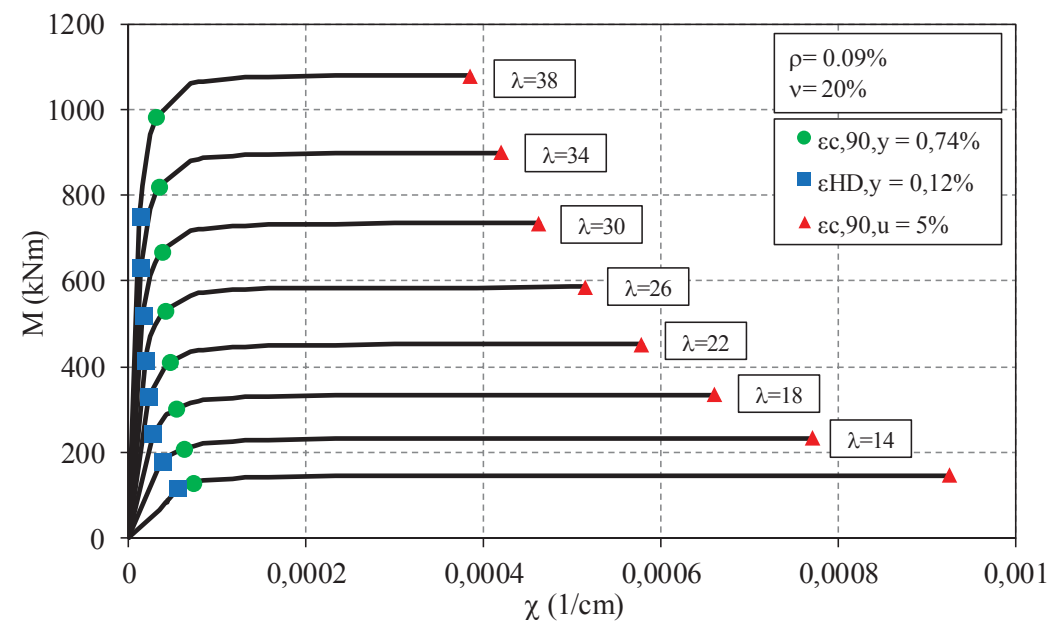

Figure 8: Moment-curvature diagrams obtained varying the cross-section slenderness ratio. 


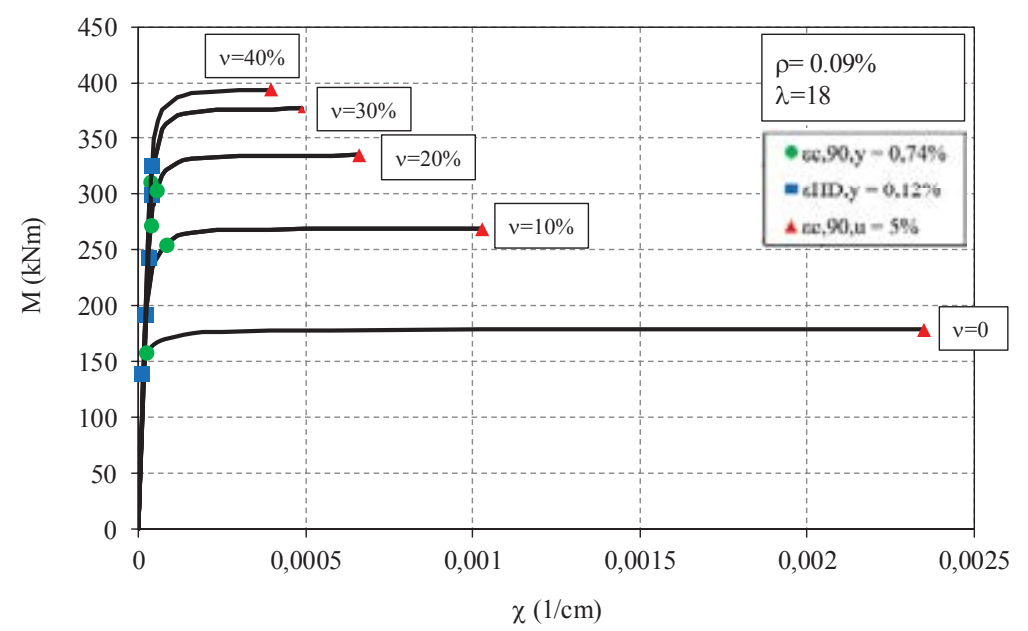

Figure 9: Moment-curvature diagrams obtained varying the dimensionless axial force.

\section{COMPARISON WITH THE NUMERICAL MODEL}

To assess their effectiveness, theoretical M- $\chi$ diagrams have been compared with those obtained through a numerical Finite Element Model (FEM) developed with the software SAP 2000 v.18 [31]. This required to model both CLT 'material' and mechanical connections and to carry-out nonlinear static analysis (e.g., pushover analyses).

\subsection{Material modelling}

CLT panels have been modelled through a two-dimensional FEM consisting of squared shell elements provided by in-plane shear and flexural stiffness, with a mesh $125 \times 125 \mathrm{~mm}$ and thickness equal to those of the panel.

Due to its cross-layered nature, the in-plane behavior of CLT panels has been simulated through an equivalent (indefinitely) elastic orthotropic material. In other terms, only the layers of boards capable of withstanding the internal forces have been assumed as effective with regards to both flexural and shear elastic stiffness (i.e., two external layers for 3-ply vertical panels). Then, Young's moduli of CLT have been obtained as it in the following:

$$
\begin{aligned}
& E_{L}=\frac{n_{l}}{n_{t o t}} E_{0} \\
& E_{T}=\frac{n_{t}}{n_{t o t}} E_{0}
\end{aligned}
$$

where EL and ET represent the reduced Young's moduli in longitudinal and transversal direction, respectively; E0 the Young's modulus of raw material, $n_{1}$ and $n_{\mathrm{t}}$ the number of layer in longitudinal and transversal direction, respectively; $n_{\text {tot }}$ the total number of layer of the panel. The same reduction has been also applied to the tangential modulus $(\mathrm{G})$ in both longitudinal and transversal direction. This material modelling gives back an acceptable representation of the material elastic properties, and is frequently adopted in literature $[9,18,24,32]$. 


\subsection{Connections modelling}

Mechanical connections are usually modelled using links, trusses or frame elements having uniaxial or biaxial behavior $[9,18,23,33]$. In the uniaxial case, HDs and ABs resist only in their primary direction (e.g., HDs in tension and ABs in shear only). In the biaxial case, both HDs and ABs resist to axial and shear forces simultaneously.

In this paper, vertical truss elements are used to model the HDs and the timber-to-timber contact, while frame elements are used for the ABs [23]. Three different elements have been defined to model the connection zones (Fig. 10):

1. HD element, consists of a no-compression truss element devoted to face the tensile forces at the bottom of the CLT panel;

2. AB element, consists of a no-compression frame element devoted to face the shear forces at the bottom of the CLT panel;

3. C element, consists of a no-tension truss element devoted to face the compression at the bottom of the panel.

The nonlinear behavior of the connection elements has been simulated through a lumped plasticity model. An elastic-perfectly plastic axial force $(\mathrm{N})$ - displacement $(\Delta)$ behavior for both HD and C elements and an elastic-perfectly plastic shear (V)-displacement $(\Delta)$ behavior for $\mathrm{ABs}$ have been assumed (Fig. 8). Concerning HDs and ABs, this modelling approach has been considered suitable also in other literature works and then effectively used to perform nonlinear analyses $[16,34]$. While for $\mathrm{C}$ elements, the elastic-perfectly plastic behavior represents an acceptable approximation of the parabola-rectangle behavior (see Fig 5a).

Due to buckling phenomenon which interests the HDs loaded in compression, their contribution has been disregarded in the model; while both hold-downs and angle brackets have been modelled with biaxial behavior but neglecting the reduction of strength due to axialshear force interaction [9].

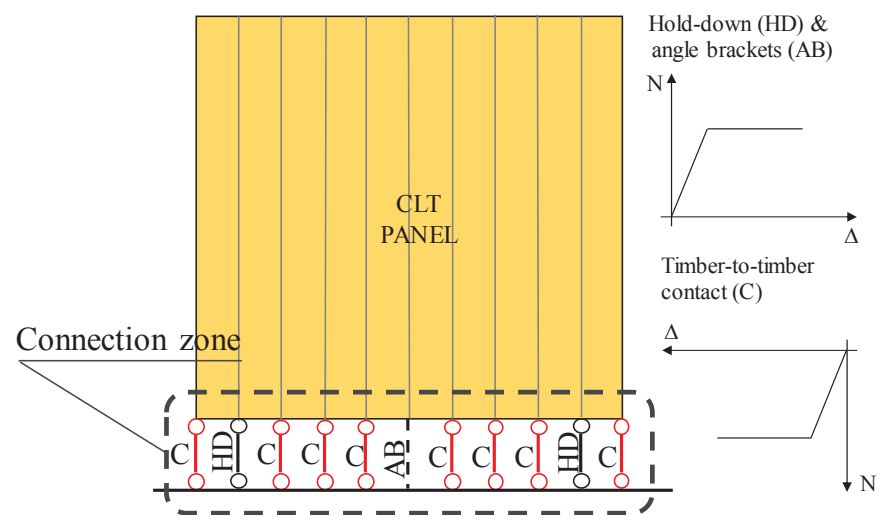

Figure 10: Representative scheme of the connection model.

\subsection{Comparisons}

In this Section the theoretical $M-\chi$ diagrams are compared with the numerical ones. At this stage of the research, only two cases have been analysed and compared: $\mathrm{M}-\chi$ diagrams obtained by variyng reinforcement area ratio $(\rho)$ and the dimensionless axial force ratio $(v)$.

Fig. 11 reports the comparison in thems of reinforcement are ratios. On the graphs are indicated the points corresponding to the first yielding of both HDs and compressed timber and those indicating the attainement of ultimate strain by timber. Numerical curves fit the theoretical ones satisfactorily: the curvature corresponding to first yielding of steel or 
compressed timber are best quantified, while ultimate curvature provided by the numerical model resulted greater than the theoeretical one.

In Fig. 12, instead, theoretical and numerical $M-\chi$ curves obtained by variyng the dimensionless axial force ratios are compared. Also in this case, a good matching between the curves in terms of yielding curvature (provided by steel in tension) is resulted, while ultimate curvature provided by the numerical model is greater than theoretical.

In general, the numerical results confirm the trend that $(i)$ the yielding curvature is reuled by steel in tension, because it precede the 'yielding' of timber under compression and that (ii) the ultimate curvature depends on ultimate strain in orthogonal to grain direction of compressed timber.

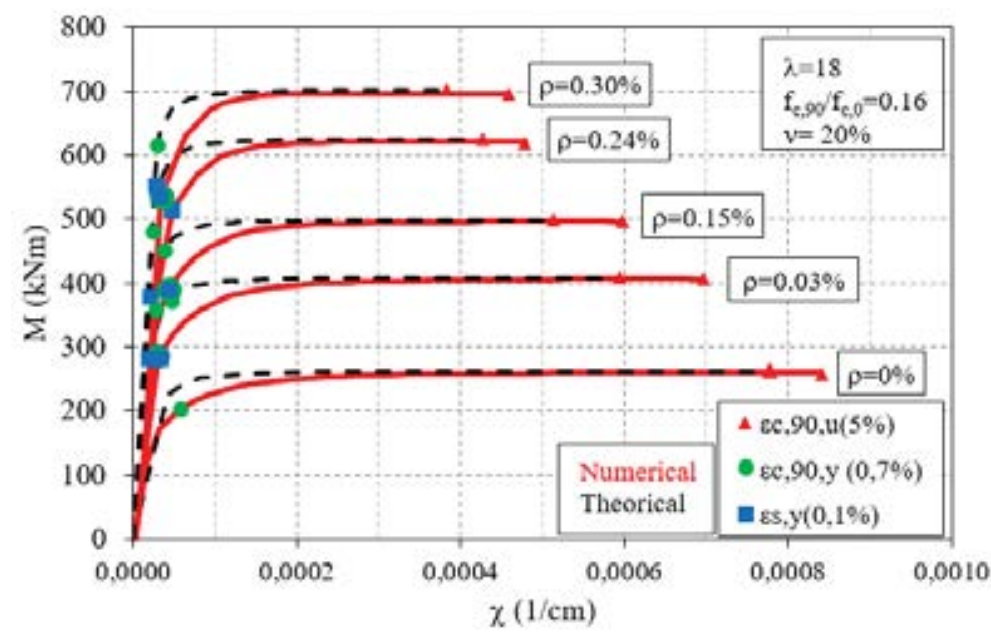

Figure 11: Comparison between theoretical and numerical $M-\chi$ diagrams by varying the reinforcement area ratios.

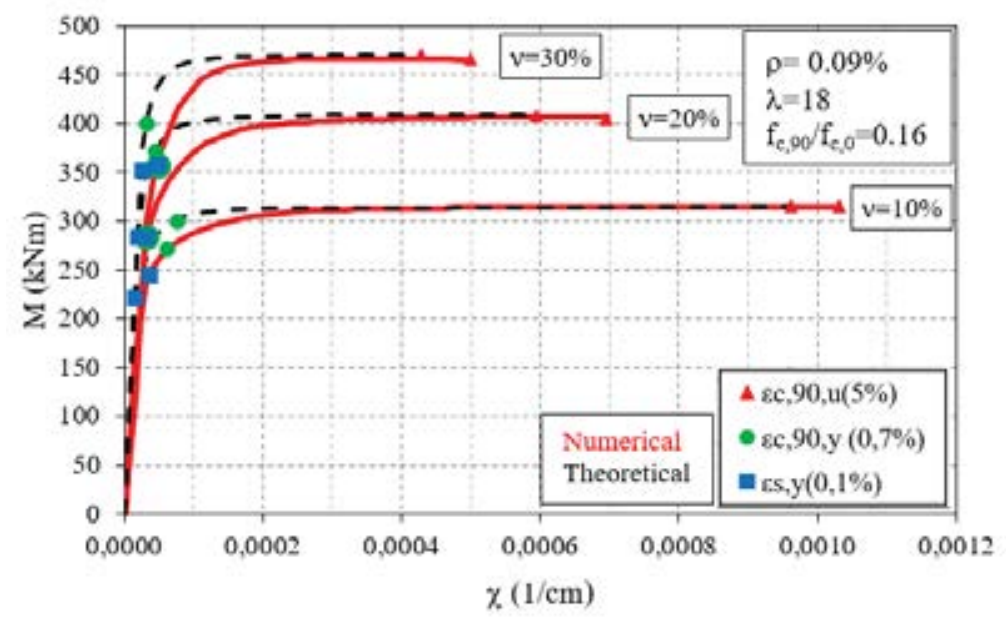

Figure 12: Comparison between theoretical and numerical $M-\chi$ diagrams by varying the dimensionless axial force ratios.

\subsection{Design-oriented formulas for estimating the ultimate curvature}

Both theoretical and numerical analyses proved that yielding in tension of HDs precedes those in compression of timber, and that ultimate curvature of the cross-section is ruled by the ultimate strain of the compressed timber.

In the light of this, it is reasonable to assume as optimal failure condition at Ultimate Limit State (ULS) for timber-to-timber contact cross-section those corresponding to HDs yielded in 
tension and timber at its ultimate strain $\left(\varepsilon_{\mathrm{c}, 90, \mathrm{u}}\right)$ in compression (Fig. 13). Based on this assumption, design-oriented formulas for evaluating both ultimate curvature and the corresponding ultimate moment of the cross-section have been defined in the following.

With regards the ultimate curvature, a closed- form formula has been obtained starting from a translation equilibrium condition on cross-section between the applied axial force $\left(N_{\mathrm{Ed}}\right)$ and tensile and compression internal resultants:

$$
\beta B x_{n, u} f_{c, 90, d}-\sum_{H D=1}^{n}\left(A_{H D} \sigma_{H D}\right)_{i}=N_{E d}
$$

where $\beta$ represents the filling coefficient of the adopted parabola rectangle normal stress distribution, assumed equal to 0.810 for rectangular cross-section (also according to Refs. $[29,36])$, B the panel width, $f_{c}, 90, d$ the design compression strength of timber in orthogonal to grain direction, $A_{H D}$ the cross-section area of the tensile-resistant element and $\sigma_{H D}$ the associated normal stress.

The maximum (or ultimate) axial force of the cross-section subjected to pure compression is:

$$
N_{R d}=B L_{p} f_{c, 90, d}
$$

where $\mathrm{L}_{\mathrm{p}}$ represents the panel length.

Dividing the eq. (8) by eq. (9) the equilibrium translation becomes:

$$
\beta \frac{x_{n, u}}{L_{p}}-\frac{\sum_{H D=1}^{n}\left(A_{H D} \sigma_{H D}\right)_{i}}{B L_{p} f_{c, 90, d}}=\frac{N_{E d}}{B L_{p} f_{c, 90, d}}
$$

They have been defined with the symbols $\omega$ and $v$ the mechanical reinforcement percentage and the dimensionless axial force, respectively:

$$
\begin{gathered}
\omega_{i}=\frac{\left(A_{H D} \sigma_{H D}\right)_{i}}{B L_{p} f_{c, 90, d}} \\
v=\frac{N_{E d}}{B L_{p} f_{c, 90, d}}
\end{gathered}
$$

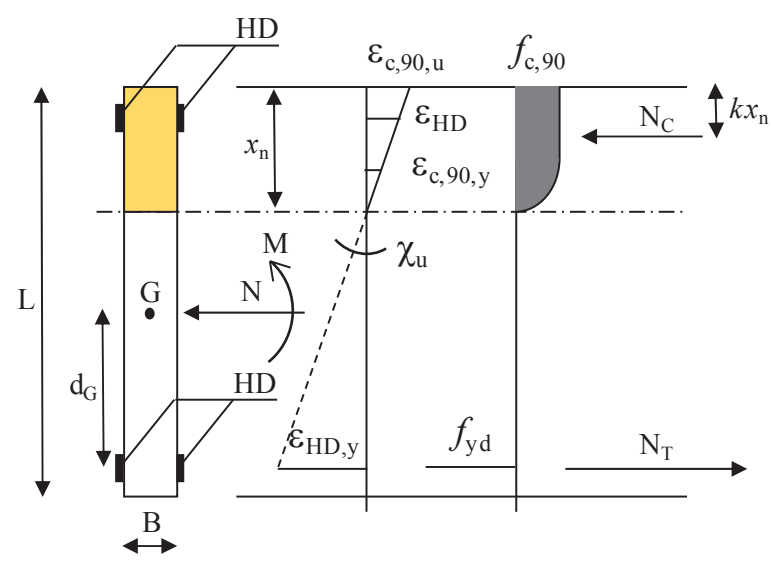

Figure 13: Failure condition for the timber-to-timber cross-section at ULS (i.e., stage III). 
By introducing $\omega$ and $v$, the equilibrium translation equation can be written as:

$$
\beta \frac{x_{n, u}}{L_{p}}=\sum_{H D=1}^{n} \omega_{i}+v
$$

In general, the ultimate curvature is given by:

$$
\chi_{u}=\frac{\varepsilon_{c, 90, u}}{x_{n, u}}
$$

where $\varepsilon_{\mathrm{c}, 90, \mathrm{u}}$ represents the ultimate strain of timber at compressed edge and $x_{\mathrm{n}, \mathrm{u}}$ the ultimate neutral axis depth. By substituting the eq. (14) in the eq. (13) the ultimate curvature of the cross-section can be expressed with the closed formula:

$$
\chi_{u}=\beta \frac{\varepsilon_{c, 90, u}}{L_{p}\left(\sum_{H D=1}^{n} \omega_{i}+v\right)}
$$

As it can be noted, the eq. (15) it easy of use. It allows to determine the ultimate curvature as a function of mechanical parameters which define the timber-to-timber connection zones without any other additional calculation. Furthermore, the eq. (15) confirms all the findings proved through the Figures 7, 8 and 9: when $\omega, v$ and $L_{\mathrm{p}}$ increase the ultimate curvature decreases. While, if the ultimate strain $\left(\varepsilon_{\mathrm{c}, 90, \mathrm{u}}\right)$ of compressed timber reduces (increases) also the ultimate curvature reduces (increases) proportionally.

The ultimate moment of the cross-section associated to $\chi_{\mathrm{u}}$ is determined through the equilibrium rotation around the center-of-gravity of the cross-section:

$$
M_{R d}\left(N_{E d}\right)=\beta B x_{n, u} f_{c, 90, d}\left(L_{p} / 2-k x_{n, u}\right)+\sum_{H D=1}^{n}\left(A_{H D} \sigma_{H D} d_{G}\right)_{i}
$$

where $k x_{\mathrm{n}, \mathrm{u}}$ represent the distance of the internal compression resultant of timber with respect to the compressed edge, with $\mathrm{k}=0.40$ and $d_{\mathrm{G}}$ the distance of the i-th tensile resistant element with respect to the center-of-gravity of the section (Fig. 13).

\begin{tabular}{lccccc}
\hline Case & $\begin{array}{c}\chi_{\mathrm{u}, \text { th }} \\
(1 / \mathrm{cm})\end{array}$ & $\begin{array}{c}\omega \\
(-)\end{array}$ & $\begin{array}{c}v \\
(-)\end{array}$ & $\begin{array}{c}\chi_{\mathrm{u}, \mathrm{CF}} \\
(1 / \mathrm{cm})\end{array}$ & $\begin{array}{c}\Delta\left(\chi_{\mathrm{u}}\right) \\
(\%)\end{array}$ \\
\hline$\rho=0.00 \%$ & 0.00092 & 0.000 & 0.20 & 0.00081 & 12 \\
$\rho=0.03 \%$ & 0.00081 & 0.027 & 0.20 & 0.00071 & 12 \\
$\rho=0.06 \%$ & 0.00073 & 0.053 & 0.20 & 0.00064 & 12 \\
$\rho=0.09 \%$ & 0.00066 & 0.080 & 0.20 & 0.00057 & 14 \\
$\rho=0.12 \%$ & 0.00060 & 0.107 & 0.20 & 0.00052 & 13 \\
$\rho=0.15 \%$ & 0.00055 & 0.137 & 0.20 & 0.00048 & 13 \\
$\rho=0.18 \%$ & 0.00051 & 0.161 & 0.20 & 0.00044 & 14 \\
$\rho=0.21 \%$ & 0.00048 & 0.187 & 0.20 & 0.00042 & 12 \\
$\rho=0.24 \%$ & 0.00044 & 0.220 & 0.20 & 0.00039 & 11 \\
$\rho=0.27 \%$ & 0.00042 & 0.240 & 0.20 & 0.00037 & 12 \\
$\rho=0.30 \%$ & 0.00039 & 0.267 & 0.20 & 0.00035 & 10 \\
\hline
\end{tabular}

Table 1: Comparisons among ultimate curvature derived by theoretical and closed-form formula obtained by varying the percentage reinforcement area ratio. 
In Table 1 and 2 are summarized and compared the values of the ultimate curvature obtained from theoretical model (indicated as $\chi \mathrm{u}$, th) with those derived the proposed closed-form formula described by the eq. (15) (indicated as $\chi_{\mathrm{u}, \mathrm{CF}}$ ). In particular, Table 1 refers to the ultimate curvature obtained by varying the reinforcement percentage ratios, while Table 2 refers to ultimate curvature obtained by varying the dimensionless axial force ratios. In the same Tables, the percentage differences between $\chi_{\mathrm{u}, \text { th }}$ and $\chi_{\mathrm{u}, \mathrm{CF}}$, indicated with the symbol $\Delta\left(\chi_{\mathrm{u}}\right)$, are also reported. The results proved that the percentage deviations $\Delta\left(\chi_{\mathrm{u}}\right)$ are quite constant and included in the interval $10-15 \%$, thus confirming that the closed-form formula gives acceptable results.

\begin{tabular}{lccccc}
\hline Case & $\begin{array}{c}\chi_{\mathrm{u}, \mathrm{th}} \\
(1 / \mathrm{cm})\end{array}$ & $\begin{array}{c}\omega \\
(-)\end{array}$ & $\begin{array}{c}\rho \\
(\%)\end{array}$ & $\begin{array}{c}\chi_{\mathrm{u}, \mathrm{CF}} \\
(1 / \mathrm{cm})\end{array}$ & $\begin{array}{c}\Delta\left(\chi_{\mathrm{u}}\right) \\
(\%)\end{array}$ \\
\hline$v=0.0 \%$ & 0.00235 & 0.080 & 0.09 & 0.00200 & 15 \\
$v=10 \%$ & 0.00102 & 0.080 & 0.09 & 0.00090 & 12 \\
$v=20 \%$ & 0.00066 & 0.080 & 0.09 & 0.00058 & 12 \\
$v=30 \%$ & 0.00049 & 0.080 & 0.09 & 0.00042 & 14 \\
\hline
\end{tabular}

Table 2: Comparisons among ultimate curvature derived by theoretical and closed-form formula obtained by varying the dimensionless axial force ratio.

\section{CONCLUSIONS}

Despite that CLT constructional technology is widely diffused in many countries, a unified approach for evaluating the flexural load-bearing and displacement capacity of the panel subjected to seismic and gravity loads has not been yet defined. Different theoretical methods are proposed in literature, whose main shortcomings consist of under evaluating the role of compressed timber in the timber-to-timber contact zone and its influence on the ductile behavior of the panels.

This paper presents a novel moment-curvature $(\mathrm{M}-\chi)$ theoretical model for CLT panels. The method, based on an iterative procedure, allowed to develops the entire M- $\chi$ diagrams and to investigate the ductile behavior of CLT accounting for the orthogonal to grain properties of compressed timber.

The influence of different parameters on the post-elastic displacement capacity of the panels has been investigated through a parametric study. The obtained results proved that: $(i)$ CLT panels are provided of good ductile behavior; (ii) increments of percentage reinforcement ratios, as well as of slenderness cross-section ratios and amount of axial force, induce significant reductions of the panels' ductility, whereas the ultimate moment increases simultaneously; (iii) the yielding curvature is ruled by HDs in tension, while the ultimate curvature depends on timber compressed in perpendicular to grain direction.

To assess the validity of the theoretical $M-\chi$ diagrams, a comparison with a finite element numerical model has been carried out. Theoretical $v s$ numerical results showed a good matching, thus confirming the validity of the theoretical method.

Finally, based on the results achieved with the parametric study, a design-oriented approach for evaluating the ultimate curvature (together with the associate ultimate moment) through a closed-form formula has been presented in the paper. Comparison of the results shown a good accordance of the closed-form formula with the theoretical approach. 


\section{REFERENCES}

[1] R. Brandner, G. Flatscher, A. Ringhofer, G. Schickhofer, A. Thiel. Cross laminated timber (CLT): Overview and development. Eur J Wood Prod, 74, 331-351, 2016.

[2] A. Iqbal. Cross Laminated Timber in New Zealand: Introduction, prospects and challenges. New Zealand Timb Design J, 22, 3-8, 2018.

[3] S. Pei, D. Rammer, M. Popovski, T. Williamson, P. Line, J.W. van de Lindt. An overview of CLT research and implementation in North America. $16^{\text {th }}$ World Conference on Timber Engineering (WCTE 2016), Wien, Austria, August 11-25, 2016.

[4] Y. Goto, R. Jockwer, K. Kobayashi, Y. Karube, H. Fukuyama. Legislative background and building culture for the design of timber structures in Europe and Japan. $17^{\text {th }}$ World Conference on Timber Engineering (WCTE 2018), Seoul, Korea, 20-23 August 2018.

[5] A. Ceccotti, C. Sandhaas, M. Okabe, M. Yasumura, C. Minowa, N. Kawai. SOFIE project - 3D shaking table test on a seven-storey full-scale cross-laminated timber building. Earth Eng Struct Dyn, 42, 2003-2021, 2013.

[6] J.W. van de Lindt, J. Furley, M.O. Amini, S. Pei, G. Tamagnone, A.R. Barbosa, D. Rammer, P. Line, M. Fragiacomo, M. Popovski. Experimental seismic behaviour of a two-story CLT platform building. Eng. Struct. 183, 408-422, 2019.

[7] I. Gavric, M. Fragiacomo, A. Ceccotti, Cyclic behaviour of typical metal connectors for cross-laminated (CLT) structures, Materials and Structures 48, 1841-1857, 2015.

[8] R. Tomasi, I. Smith. Experimental characterization of monotonic and cyclic loading response of CLT panel-to-foundation angle bracket connection. J Mater Civ Eng, 27 (6), 2015.

[9] M. Izzi, D. Casagrande, S. Bezzi, D. Pasca, M. Follesa, R. Tomasi. Seismic behavior of Cross-Laminated Timber structures: A state-of-the-art review. Eng Struct 170, 45-52, 2018.

[10] K.W. Johansen. Theory of timber connections. Int Ass for Bridge and Struct Eng 9, 249$262,1949$.

[11] EN 1995-1-1: 2004. Eurocode 5: Design of timber structures - Part-1-1: general rules and rules for buildings. European Committee for Standardization (CEN), Brussels, Belgium; 2003.

[12] A. Sandoli, C. D’Ambra, C. Ceraldi, B. Calderoni, A. Prota. Sustainable CrossLaminated Timber Structures in a Seismic Area: Overview and Future Trends. Applied Science, 11, 2078, 2021. doi.org/10.3390/app11052078.

[13] F. Sarti, A. Palermo, S. Pampanin. Quasi static cyclic testing of two-thirds scale unbonded posttensioned rocking dissipative timber walls. J. Struct Eng 142, E40115005, 2016.

[14] Latour, M.; Rizzano, G. Seismic behavior of cross-laminated timber equipped with traditional and innovative connectors. Arch Civ Mech Eng 17, 382-399, 2017.

[15] R. Scotta, L. Marchi, D. Trutalli, L. Pozza. A dissipative connector for CLT buildings: Concept, design and testing. Materials 9, 139, 2016.

[16] G. Tamagnone, G. Rinaldin, M. Fragiacomo. A novel method for nonlinear design of CLT wall systems. Eng Struct 167, 760-771, 2018. 
[17] I. Lukacs, A. Bjornfot, R. Tomasi. Strength and stiffness of cross laminated timber (CLT) shear walls: State-of-art of analytical approaches. Eng Struct 178, 136-147, 2019.

[18] D. Vassallo, M. Follesa, M. Fragiacomo. Seismic design of a six-storey CLT buildings in Italy. Eng Struct 175, 322-338, 2018.

[19] ONORM B 1995-1-1, Eurocode 5: Design of Timber Structures - Part 1-1: General Common Rules and Rules for Buildings - National Specification for the Implementation of ONORM EN 1995-1-1, National Comments and National Supplements, Austrian Standards Institute (ASI), 2015 (in German).

[20] E. Serrano, B. Enquist. Compression strength perpendicular to grain in cross-laminated timber (CLT). $11^{\text {th }}$ World Conference on Timber Engineering (WCTE 2010), Riva del Garda, Italy, 2010.

[21] E. Gasparri, F. Lam, Y. Liu. Compression perpendicular to grain behaviour for the design of a prefabricated CLT façade horizontal joint. $16^{\text {th }}$ World Conference on Timber Engineering (WCTE 2016), Wien, Austria, August 11-25, 2016.

[22] R. Brandner. Cross laminate timber (CLT) in compression perpendicular to plane: testing, poperties, design and recommendations for harmonizing design provisions for structural timber products. Eng Struct 17, 944-960, 2018.

[23] A. Sandoli, C. D’Ambra, C. Ceraldi, B. Calderoni, A. Prota. Role of perpendicular to grain compression properties on the seismic behaviour of CLT walls. Journal of Building Engineering, 34, 101889, 2021.

[24] A. Sandoli, D. Moroder, S. Pampanin, B. Calderoni. Simplified analytical models for coupled CLT walls. $16^{\text {th }}$ World Conference on Timber Engineering (WCTE 2016), Wien, Austria, August 11-25, 2016.

[25] EN 338, Structural Timber - Strength Classes, European Committee for Standardization (CEN), 2016.

[26] EN14080, Timber Structures - Glued Laminated Timber and Glued Solid Timber- Requirements, European Committee for Standardization (CEN), 2013.

[27] European Committee for Standardization (CEN) Eurocode 2: Design of concrete structures -Part a-a: General rules and rules for buildings; 2004.

[28] L. Franco, L. Pozza, A. Saetta, D. Talledo, Enhanced N-V interaction domains for the design of CLT shear wall based on couple interaction models. Eng Struct 231, 111607, 2021.

[29] ETA-14/0349. (2019). European Technical Assessment, issued in accordance with Regulation EU n ${ }^{\circ} 305 / 2011$.

[30] EN 1993-1. Eurocode 3: Design of steel structures - Part 1-1 general rules and rules for buildings. European Committee for Standardization (CEN), Brussels, Belgium; 2003

[31] SAP 2000 (v.18). Structural Analysis Program, CSI.

[32] A. Sandoli, B. Calderoni. The rolling shear influence on the out-of-plane behavior of CLT panels: A comparative analysis. Buildings, 10(3), 42, 2020.

[33] S. Pei. J. van de Lindt, M. Popovski. Approximate R-factor for cross-laminated timber (CT) shear walls: state-of-art of analytical approaches. Eng Struct 178,136-147, 2019. 
[34] L. Embury-Williams, E. Karakabey (Eds.), Application of Analysis Tools from NEW Buildings Research Network in Design of a High-Rise Wood Building. NSERC: Strategic Research Network on Innovative Wood Products and Building Systems (New Buildings), 2014. 